\title{
WITTGENSTEIN COMO PÓS-MODERNO: O CASO DA FILOSOFIA DA EDUCAÇÃO MATEMÁTICA
}

\author{
WITTGENSTEIN COMO POST-MODERNO: EL CASO DE LA FILOSOFÍA DE LA \\ EDUCACIÓN MATEMÁTICA
}

\section{WITTGENSTEIN AS POST-MODERN: THE CASE OF THE PHILOSOPHY OF MATHEMATICAL EDUCATION}

DOI: http://dx.doi.org/10.9771/gmed.v11i3.28925

\author{
Guilherme Wagner ${ }^{1}$ \\ Everaldo Silveira ${ }^{2}$
}

\begin{abstract}
Resumo: O presente artigo investiga a gênese das teses pós-modernas e a maneira como a filosofia de Wittgenstein tem sido utilizada para acoplar ao campo da Educação Matemática as perspectivas da agenda pós-moderna. Nesse tocante, tomamos como guia metodológico dessa pesquisa o percalço histórico e teórico das teses pós-modernas, a confrontação com os originais do 'primeiro' e ‘segundo' Wittgenstein, assim como, a partir dos paralelos ideológicos com a filosofia heideggeriana, base teórica da agenda pós-moderna (DELLA FONTE, 2006), evidenciar a filosofia wittgensteiniana como expressão de sua época. Concluímos que tal acoplamento é uma falsificação da filosofia de Wittgenstein em prol da proliferação de mitos pós-modernos e identitários no campo.
\end{abstract}

Palavras-chave: Filosofia da Educação Matemática. Pós-modernismo. Wittgenstein

Resumen: El presente artículo investiga la génesis de las tesis posmodernas y la manera como la filosofía de Wittgenstein ha sido utilizada para acoplar al campo de la Educación Matemática las perspectivas de la agenda posmoderna. En este sentido, tomamos como guía metodológica de esa investigación el percance histórico y teórico de las tesis posmodernas, la confrontación con los originales del primero y segundo según Wittgenstein, así como, a partir de los paralelos ideológicos con la filosofía heideggeriana, base teórica de la agenda posmoderna (DELLA FUENTE, 2006), evidenciar la filosofía wittgensteiniana como expresión de su época. Concluimos que tal acoplamiento es una falsificación de la filosofía de Wittgenstein en favor de la proliferación de mitos posmodernos e identitarios en el campo.

Palabras clave: Filosofía de la Educación Matemática. El posmodernismo. Wittgenstein

Abstract: This paper investigates the genesis of postmodern theses and how Wittgenstein's philosophy has been used to couple the perspectives of the postmodern agenda to the field of mathematical education. In this regard, we take as a methodological guide to this research the historical and theoretical undermining of postmodern theses, the confrontation with the originals of the 'first' and 'second' Wittgenstein, as well as from the ideological parallels with Heidegger's philosophy, theoretical basis of the postmodern agenda (DELLA FONTE, 2006), to emphasize Wittgenstein's philosophy as an expression of his time. We conclude that such coupling is a falsification of Wittgenstein's philosophy for the proliferation of postmodern and identity myths in the field.

Keywords: Philosophy of Mathematics Education. Postmodernism. Wittgenstein

\section{Introdução}

O presente artigo investiga a gênese das teses pós-modernas e a maneira como a filosofia de Wittgenstein tem sido utilizada para acoplar ao campo da Educação Matemática as perspectivas da agenda 
pós-moderna. Nesse tocante, tomamos como guia metodológico dessa pesquisa o percalço histórico e teórico das teses pós-modernas, a confrontação com os originais do 'primeiro' e 'segundo' Wittgenstein, assim como, a partir dos paralelos ideológicos com a filosofia heideggeriana, base teórica da agenda pósmoderna (DELLA FONTE, 2006), evidenciar a filosofia wittgensteiniana como expressão de sua época.

A partir desse estudo discutimos criticamente os mitos relacionados a semiologização da realidade, a defesa de uma ética desconstrucionista, o mito do eurocentrismo e por fim uma reanalise da perspectiva neopragmática de ensino da matemática baseada na filosofia wittgensteiniana como sendo neotecnicista. Nesse tocante, concluímos que a filosofia de Wittgenstein é estranha ao corpo teórico da agenda pósmoderna, assim como, seu uso tem sido uma maneira de justificar a possibilidade da incorporação dessas teses.

\section{Paralelos ideológicos da filosofia de Wittgenstein com Heidegger}

Compreender a filosofia wittgensteiniana, e suas continuidades nas descontinuidades, passa por compreender o espírito da época. Entretanto, o espírito do tempo não está vinculado a uma visão absoluta do Espírito hegeliano que leva sempre ao aprimoramento, e sim compreendido como expressão ideológica da materialidade. Portanto, a ideologia é compreendida aqui como

o imperativo de se tornar praticamente consciente do conflito social fundamental - a partir dos pontos de vista mutuamente excludentes das alternativas hegemônicas que se defrontam em determinada ordem social - com o propósito de resolvê-lo pela luta. (MÉSZÁROS, 2004, p.66, grifos do autor)

Dessa forma, expor paralelos ideológicos entre as filosofias de Heidegger e Wittgenstein tem três dimensões. A primeira se refere ao fato de os dois filósofos apresentarem um acintoso movimento de descontinuidade, beirando a ruptura, entre suas filosofias durante o período fascista europeu. O segundo que esse movimento expressa os movimentos prático conscientes das coletividades sociais as quais pertenceram assim como suas contradições inerentes. O terceiro ao fato de serem de fato paralelos, isto é, por mais semelhantes que possam parecer suas filosofias expressam no sentido ontológico e racional formas diferentes de pensar e organizar o mundo.

O primeiro Heidegger, anterior ao seminário de verão de 1935, compreendia a metafísica como uma questão propositiva e positiva para a relação entre Ser e Ente, isto é, capaz de auxiliar na resolução das questões sociais postas. Para este Heidegger (2005a), que se expressa de maneira completa e autêntica em sua obra O Ser e o Tempo, onde o mesmo expõe os conflitos inerentes que o ser-aí e o das Man, sendo o último aquele que domina o ser-aí dando pouca margem para uma autonomia deste, tornando sua filosofia contraditória, pois ao mesmo tempo que o ser-aí autêntico buscava sua autenticidade, das Man não permite.

A expressão teórica de Heidegger, e sua contradição insolúvel para sua filosofia é manifestação ideológica das contradições sociais inerentes a uma sociedade técnica, que segue princípios da economia de tempo, da eficiência e que desumaniza o ser-aí ao ponto de considerá-lo como objeto. Igualmente, pensar essa solução é pensar uma forma de organização social que rompa com esse domínio: para o filósofo alemão esta solução para uma outra forma de relacionar ser-aí e das Man, entre o ser humano e a técnica, foi o 
movimento nacional-socialista - o nazismo. Essa insolubilidade, como já apontado em Wagner e Silveira (2017), e em consonância com Lukács (2012), é expressão da compreensão anistórica do Ser, isto é, a história é externa a constituição ontológica do Ser: primeiro o Ser, e depois de constituir o Ser o estudo do Tempo, O Ser e o Tempo.

Paralelamente, no Tractatus existe uma defesa de que tudo que ocorre no mundo é casuístico, não é possível compreender seu sentido como mundo, e o critério da verdade está limitado a uma concepção de manipulabilidade do cotidiano. O que Wittgenstein (1968) expõe como critério da verdade é a expressão de das Man heideggeriano e que igualmente o processo de tomada de consciência a ação para a mudança social é impossível, primeiro porque tudo é casuístico, segundo porque o sujeito não pertence ao mundo, mas é antes de tudo o limite do mundo, e terceiro porque sobre tudo aquilo que não é possível expressar como verdade manipuladora das coisas cotidianas deve-se calar. No entanto, enquanto Heidegger (2005a) advoga uma nova relação social com a técnica a partir da derrelição de um novo homem a partir do nazismo, a perspectiva do Tractatus é a perspectiva britânica de uma nação vencedora da primeira guerra, onde o domínio global da técnica representa o prestígio e o avanço das forças sociais e do progresso encontrando seu sentido na contemplação místico-religiosa do mundo, buscando o sentido fora dele.

Por outro lado, inicia-se um processo de descontinuidade na filosofia wittgensteiniana a partir da crise 29, da ascensão do fascismo europeu e das experiências de vida como professor, arquiteto e a Viena pós-guerra. Há um declínio da sociedade europeia com o avanço das forças fascistas e a incapacidade das então potências britânicas e francesas de lidar com a situação. Wittgenstein bebe desse espírito materializando em um processo contínuo de um novo fazer filosófico configurando-se em novas perspectivas sobre a linguagem e o fazer da filosofia. A virada linguística wittgensteiniana, como questionamento de sua filosofia presente no Tractatus, é também expressão da materialidade social que vinha questionando os andamentos da sociedade europeia: entre o fascismo, o liberalismo e o socialismo. A obra de Wittgenstein (1991) é fruto dessas indagações. Este permitir questionar-se o Tractatus, obra que ele mesmo considerava completa e que resolvia todos os problemas filosóficos, é então expressão de um questionamento da humanidade para consigo mesma.

Tal virada filosófica também se fará presente na filosofia de Heidegger, entretanto, seu conteúdo é oposto ao de Wittgenstein, apesar das tentativas contínuas de relacionar suas teses. Para o Heidegger pósseminário de verão de 1935 a metafísica e a ontologia se tornarão exemplos niilistas do mundo, onde a busca constante pelo ente para discutir o Ser faz com caíamos fora do Ser, isto é, a centralidade da razão nas narrativas filosóficas, nas buscas pelo Ser, acaba fazendo com que percamos o Ser. Portanto, a metafísica do ente como busca pelo Ser centrado na razão, o logocentrismo, é o que tem feito com que desde os gregos percamos as experiências autênticas do Ser, assim, o compromisso dessa nova filosofia é a desconstrução do logocentrismo. Até janeiro de 1934 todas as obras de Heidegger defendiam os aspectos positivos da metafísica, da centralidade da razão, etc. (FAYE, 1996), a questão que se coloca é o que houve entre 1934 e o seminário de verão de 1935 para houvesse esse movimento brusco em sua filosofia? 
A obra de Faye (1996) trata de analisar as narrativas de Heidegger e as suas transformações durante este período em especial, e durante toda sua obra. Comprova documentalmente Faye que esta mudança nos discursos heideggerianos são resultados de um conflito interno entre os filósofos 'oficiais' do nazismo.

Em 1934, Krieck escreve o artigo "Mito Germânico e Filosofia Heideggeriana" na revista Volk im Werden em que atacam as teses de 'O Ser e o Tempo' e da conferência 'O que é a Metafísica?' afirmando que a filosofia de Heidegger tem origens diversas, muitas delas não-germânicas, e as suas teses da angústia e do cuidado visam ao nada construindo uma metafísica do niilismo, assim como um discurso onde prevalecia o Logos sobre o Mythos (FAYE, 1996). Esse problema da filosofia como expoente niilista é visto por Krieck (apud FAYE, 1996, p. 402) como uma questão de toda a filosofia “de Heráclito e Parmênides" até aquele momento. Heidegger (1991) anos mais tarde, no Nachwort de 1943, chamará esta de uma polêmica cega, mas sem mencionar Krieck incorporará em 1935, na Introdução a Metafísica a ideia de superação do niilismo, sem superar a Metafísica, configurando o niilismo como essa busca pelo ente sem encontrar o Ser. Entretanto, no Nachwort de 1943 e no Einleitung de 1949 - respectivos posfácio e introdução a obra "O que é a metafísica?" - que Heidegger acatará a equivalência de Krieck e afirmará que a superação do niilismo necessita da superação da metafísica, e, portanto, a metafísica seria niilista sem no entanto descartar o Ser (FAYE, 1996). O autor francês ainda destaca que a obra O que é a metafísica? datada de 1929 nada tinha nesse tempo qualquer menção a superação da metafísica e do niilismo. Esta mudança de sua filosofia é feita durante as conferências sobre Nietzsche culminando no pós-guerra, em pleno período de desnazificação, a afirmar que os regimes fascistas seriam eles mesmos os causadores do niilismo. Entretanto, em 1936 quando lecionava sobre Schelling afirmou que Mussolini e Hitler era os dois únicos homens capazes de superar e ser resistência ao niilismo, mais do que isso, Tertulian denuncia que Heidegger retira esses trechos das publicações futuras de suas conferências (FAYE, 1996).

Por outro lado, a tese crítica do logocentrismo, também proferida por Krieck, será acatada por Heidegger de uma maneira ainda mais peculiar, bebendo da postura antilogocentrica da revista do Instituto Goering, Heidegger constrói a ideia da desconstrução do logocentrismo a partir do antilogocentrismo que se estabelece em volta da revista (FAYE, 1996).

Portanto, o segundo Heidegger é uma tentativa de resposta do filósofo as críticas que vinha recebendo por parte dos teóricos oficiais do regime alemão. É nesse aspecto que entra a falsificação de sua filosofia por si mesmo. Durante a comissão de desnazificação da universidade de Freiburg ele utiliza sua tese de superação da metafísica como uma tese supostamente crítica ao regime nazista, isto é, diz que não estava querendo ser aceito pelo regime nazista, mas sim, fazendo oposição. Dessa maneira, com a derrota do nazismo e o processo de desnazificação, muito do trabalho teórico nazista é perdido, e Heidegger aproveita-se desse fato para falsificar a si mesmo, e se postular como real opositor e crítico ao nazismo, sendo mais do que isso, afirma que sua filosofia é a única que realmente é capaz de combater o fascismo sendo inclusive os opositores que deram a vida na luta contra o nazismo aqueles que o produziram (HEIDEGGER, 2005b).

Portanto, as teses centrais da agenda pós-moderna, que tem raízes na filosofia heideggeriana (DELLA FONTE, 2006), são em verdade extensão das filosofias oficiais do período nazista, e nesse tocante, 
a agenda pós-moderna tem sua gênese na aceitação e apropriação de Heidegger das críticas recebidas por seus opositores. Nessa direção, as teses da extrema-direita são incorporadas a uma filosofia dita de esquerda por parte da filosofia francesa (Derrida, Foucault, Deleuze).

Enquanto Heidegger estava do lado do movimento nazista Wittgenstein se alistava para trabalhar como ajudante nos ambulatórios e hospitais (MONK, 1997). Assim como o fascismo europeu influenciou Heidegger, o mesmo ocorre com Wittgenstein. Entretanto, essa influência não é tão documentada e direta quanto a de Heidegger.

O trabalho de Conde (2004) busca resguardar a concepção crítica de Wittgenstein com relação a linguagem, e a sociedade, das teses relativistas e ceticistas. Para Conde (2004) não há um abandono do logos nos discursos wittgensteinianos, há antes de tudo uma crítica a razão como instrumento de representação total do mundo e que se caracteriza por permitir a inteligibilidade de uma essência transcendental deste mundo. A tentativa de Conde (2004) está de um lado em contrariar as afirmações rortyanas de que Wittgenstein seja relativista e as afirmações de Apel de que ele tenha abandonado a razão como forma de pensar o mundo. Para Conde (2004) a racionalidade nas Investigaçôes Filosóficas (IF) se caracteriza como uma teia de usos e regras que emergem dos jogos de linguagem e das gramáticas das formas de vida. Esta teia é a maneira como Wittgenstein concebe o conceito de sistema, longe de ser uma visão totalizante do mundo seria uma vista panorâmica do mundo, holística, multifacetada em suas mais diversas possibilidades. Dessa forma, o modelo de racionalidade do 'segundo' Wittgenstein se manifesta não como uma atividade que organiza a análise da linguagem em busca de sua essência lógica, mas sim como uma análise que busca, numa visão panorâmica, expressar e descrever as mais diversas possibilidades de uso da linguagem dentro de um jogo de linguagem.

Dessa forma, seguindo as colocações de Conde (2004) não é possível afirmar que há uma desconstrução do logocentrismo na filosofia do 'segundo' Wittgenstein apesar de ser possível compreender nele uma visão antimetafísica da filosofia. Em suma, para Conde (2004) não há uma interrelação entre a visão antimetafísica e uma crítica ao logocentrismo.

Wittgenstein $(1968,1991)$ silencia-se frente a essência material do mundo. No entanto, a ideia de que Wittgenstein faz a razão passar por um processo desconstrução é altamente problemática. Primeiro porque apesar de expor uma tendência antimetafísica, de superação da metafísica como argumento transcendental do ente, tanto no Tractatus quanto nas $I F$, isto não the remove o fato do mesmo ter uma compreensão de mundo místico-religiosa (BADIOU, 2013; MARGUTTI, 2006). Isto é, por mais antimetafísica que seja a forma filosófica de suas obras, não obstante, o conteúdo de sua filosofia adquire uma posição ontológica expressa por seu silêncio manifesto a partir da doutrina do dizer e mostrar. Assim, em Wittgenstein não há um movimento que prefere o mito à razão, mas sim, uma síntese característica do pensamento cristão: não há a fé e a razão, as duas são indissociáveis em uma visão ontológico-religiosa.

Dessa forma, a analítica filosófica de Wittgenstein é antes de tudo um mostrar os usos da linguagem em contraposição a uma visão essencialista da linguagem. A linguagem como partícipe do mundo, emergente dele, tem seu sentido ontológico igualmente expresso pelo sentido cristão: a essência da linguagem como parte do mundo é externa ao mundo, e quando a procuramos no mundo unicamente 
podemos contempla-la a partir da análise gramatical dos jogos de linguagem. Isto é, se a essência da linguagem está na gramática, o está porque a partir da gramática podemos mostrar o sentido do mundo, sem nada dizer sobre ele, de maneira que tudo que pode ser dito é metafísico e estará em contradição com sua visão ontológica do mundo.

Portanto, não há em Wittgenstein uma crítica as grandes narrativas, mas sim uma defesa silenciosa e contemplativa da visão cristã do mundo. E como já afirmado, para não chocar as interpretações da realidade com essa visão cristã cabe a linguagem somente descrever os usos, expor a gramática, e reificar o cotidiano a partir da filosofia visto que a cotidianidade já é dada e o sujeito que age nela nada pode mudar da realidade no seu sentido essencial, dado que tudo que ocorre continua casuístico e caótico. Assim, a crítica de Wittgenstein ao afirmar que a filosofia deve deixar tudo como está não se relaciona com o fim das grandes narrativas e do cair fora do Ser heideggeriano, mas antes de tudo, a sua concepção de mundo cristã.

\section{Implicações dos limites da filosofia de Wittgenstein para a Educação Matemática: um diálogo crítico com o campo}

A seção que segue busca analisar, a partir de um diálogo crítico com alguns interlocutores wittgensteinianos na Educação Matemática, como os limites da filosofia wittgensteiniana se manifestam no campo, e ao mesmo tempo, como esses limites procuram ser superados pelos interlocutores. A escolha desses interlocutores foi feita a partir de dois critérios principais, o primeiro referente a influência dentro do campo e o segundo referente à perspectiva interna a que pertencem. Os autores escolhidos foram Antonio Miguel, Denise Vilela, Cristiane Gottschalk, Gelsa Knijnik, Claudia Duarte e Fernanda Wanderer. Os dois primeiros por sua ligação com uma perspectiva terapêutico-desconstrucionista da filosofia wittgensteiniana, as três últimas por suas produções teóricas relacionando Foucault e Wittgenstein nos estudos etnomatemáticos, e Gottschalk por seus trabalhos em prol do esclarecimento da natureza do conhecimento matemático na perspectiva wittgensteiniana e a defesa de uma educação neopragmática. Os artigos utilizados nessa reflexão deveriam, por um lado trazer em si reflexões preferencialmente filosóficas com relação a teoria wittgensteiniana na Educação Matemática, e por outro, quando existente mais de um, foi assumido o critério de relevância para o campo a partir das citações da plataforma Google Scholar.

Miguel (2016), baseando-se em Rorty, traz a subdivisão dos wittgensteinianos em dois grupos: os terapêuticos de um lado e os pragmáticos de outro, sendo a principal diferença entre eles a recusa dos pragmáticos em seguir a visão antiteórica do filósofo austríaco. Particularmente, essa divisão carece de sentido, visto que por mais que haja a exposição de uma forma antiteórica em Wittgenstein, ainda assim, seu conteúdo se revela teórico. Nessa direção, as diferentes interpretações sobre a filosofia wittgensteiniana não são resultado de um estudo aprofundado do autor como poderíamos esperar, mas antes, das maneiras que os interlocutores buscam complementar sua filosofia, visto que esta, a partir do silêncio ontológico carece de uma teoria social e da história como já exposto anteriormente. Essa complementação se apresenta de diferentes formas, mas sendo mais corriqueira os usos de autores pós-estruturalistas como Derrida e Foucault, adotando assim uma intepretação de Wittgenstein como um autor pós-metafísico (MIGUEL et 
al, 2010; KNIJNIK e DUARTE, 2010), sendo para Miguel et al (2010) uma perspectiva pós-estruturalista assim como a foucaultiana. Segundo Miguel (2016, p. 373) essa postura pós-metafísica

\begin{abstract}
embora invista e sempre continue a investir contra a metafísica, ao reconhecer, porém, ser essa luta inglória ou improdutiva, lida não com o problema genérico e abstrato da luta contra a metafísica, mas a luta contra problemas metafísicos em cada uma de suas manifestações contextuais, produzindo-se armas que evitem que deles nos tornemos prisioneiros e dissolvendo-os enquanto problemas, ao mostrar que eles podem ser vistos de outras maneiras, sob outras perspectivas. Esse tipo de estratégia é o que caracteriza, de certo modo, uma atitude terapêutico-gramatical diante de um problema metafísico, quer em suas manifestações no domínio da investigação acadêmica, quer no domínio mais amplo de nossas ações em todos os campos de atividade humana.
\end{abstract}

Existe, no entanto, outra ressalva: dentre os autores poucos são aqueles que buscam sustentar suas posições com base na análise da obra original das IF, menor ainda são as menções ao Tractatus, principalmente se considerarmos que para Wittgenstein as $I F$ somente poderiam ser compreendidas em sua totalidade se tomada de um estudo aproximado com o Tractatus. Nos momentos em que o Tractatus é citado ocorre simplesmente uma construção de um espantalho reduzindo esta obra somente a visão referencial da linguagem, ignorando a doutrina do dizer e mostrar, as posições sobre a ética e estética, e mais do que isso, a percepção de como a concepção de 'matemática' presente nas duas obras são dotadas de uma linha de continuidade muito poderosa. Em suma, no campo se tornou recorrente ignorar o Tractatus como uma obra digna de estudo, e esta uma contradição explícita, visto o Tractatus ter sido a única obra originalmente publicada e preparada por Wittgenstein.

\title{
O posfácio de Antonio Miguel: um contrabalanço
}

O posfácio de Miguel (2013) está presente no livro de Vilela (2013) que se baseou na tese desta autora de 2007 sobre as potencialidades de Wittgenstein para a ampliação das adjetivações da matemática e as tensões presentes no campo. Nesse posfácio Miguel busca explicar em linhas gerais o movimento da pergunta de pesquisa da autora que, saindo do campo específico da Etnomatemática, foi se voltando mais fortemente para o campo próprio da filosofia da educação matemática. E para justificar esse movimento realiza um balanço das perspectivas teóricas até então existentes ao mesmo tempo que busca explicitar a pouca relevância dada até então a filosofia wittgensteiniana exortando à comunidade da Educação Matemática a utiliza-la.

Citando as perspectivas de Bachelard, Lakatos, Kuhn e Aleksandrov (em língua portuguesa, Caraça) Miguel (2013, p. 326) afirma que o problema dessas perspectivas é que recorreram a "metanarrativas globais, desenvolvimentistas, etapistas e estruturalistas, como também, não chegaram a questionar a crença em sua [da matemática] unicidade e universalidade." Tendo elas então se diversificado em cima de "invariantes estruturais que foram eleitos para explicar o desenvolvimento" (p. 326).

Às perspectivas materialistas histórico-dialéticas de Caraça e Aleksandrov et al (1963) por mais que acionassem "explicitamente elementos externos ao próprio campo da atividade matemática" como questões econômicas, geopolíticas, culturais, etc., o fizeram a partir da eleição de uma estrutura apriorística e invariante de enunciados das leis da dialética materialista que explicariam o desenvolvimento das 
matemáticas, culminando em uma concepção etapista do processo, afirma Miguel (2013). De fato, as leis da dialética são tomadas como enunciados universais na filosofia hegeliana, onde o espirito absoluto tende a partir de um processo de tese e antítese produzir uma síntese que supere a questão antagonista anterior. Entretanto, no materialismo histórico-dialético há uma inversão total nessa concepção, primeiro por ela ser materialista e depois por ser histórica. A dialética não é compreendida então como um conjunto de regras que precisam ser vistas, encontradas ou aplicadas a realidade para ser possível explica-la. Um dos princípios fundamentais do materialismo histórico-dialético é permitir que a materialidade seja guia da pesquisa e do conhecimento, em que a dialética não é um construto metafísico, mas antes, dinâmica histórica que emerge da materialidade. Em suma, a visão criticada por Miguel (2013) é a da dialética hegeliana que, de fato, influenciou a concepção marxista sendo, entretanto, por ela transformada. Dessa forma, quando estudamos os trabalhos marxianos d'O Capital, ou então os trabalhos de Aleksandrov, não estamos vendo a aplicação das leis da dialética, mas antes de tudo a exposição da dinâmica da materialidade que se expressa de maneira dialética. Este erro filológico é característico de um intérprete de Wittgenstein visto que na filosofia do austríaco não existem as possibilidades de uma teleologia, muito menos de uma causalidade posta, reinando na cotidianidade a questão do caos e da heterogeneidade: onde tudo é casuístico. Isto faz com Miguel (2013) caia num segundo equívoco ao querer ver em Aleksandrov uma defesa etapista da matemática caracterizando tais etapas como um movimento legal da matemática em direção a sua dimensão universal.

Em Aleksandrov et al (1963) se faz presente uma concepção teleológica e causal da sociedade, onde as estruturas determinam e são determinadas pelos sujeitos. Nesse aspecto, Aleksandrov et al (1963) não estão elegendo etapas históricas do desenvolvimento matemática a partir da aplicação de uma lei dialética, mas antes de tudo, evidenciando no movimento histórico a dinâmica dialética entre estrutura e teleologia. Por outro lado, Miguel (2013) advoga de uma concepção negativa da concepção de universal na obra de Aleksandrov et al (1963). A concepção de universal e de totalidade são em grande parte incompreendidas de um lado pelo ataque liberal de Arendt (1979), que buscou comparar as concepções filosóficas de totalidade com o totalitarismo, e de outro, pela desconstrução da metafísica inaugurada por Krieck e acatada por Heidegger. Para a crítica a essa concepção de universal era necessário antes de tudo a construção de um espantalho teórico, dando ao universal as características de invariável, imutável e onipresente. Esta concepção de universal é cristã, enquanto que a concepção de universal do materialismo histórico-dialético não é nem invariável, nem imutável, muito menos onipresente. Em verdade, o universal para o materialismo histórico-dialético é a expressão maior do gênero humano para determinada época e cultura, portanto, o universal é mutável, e seu desenvolvimento está associado ao desenrolar-se da história da própria cultura e do bic et nunc que está inserida.

\section{A semiologização da realidade}

A semiologização da realidade é o conceito que podemos empregar para compreender de um lado o fetiche pela linguagem, a partir dos jogos de linguagem, e de outro a reificação do cotidiano. Assim, a semiologização da realidade é a crença de que a linguagem estrutura a realidade, e que somente a partir da 
linguagem podemos acessar, agir, refletir e compreender a realidade, ao ponto de ela mesma ser uma sobreposição de jogos de linguagem formando teias multifacetadas inter-relacionadas. Mais do que isso, as formas de vida são engolidas por essas teias ao ponto de não ser possível mais dissociar o que seriam formas de vida dos jogos de linguagem. Desta compreensão, os jogos de linguagem passam a ser vistos como discurso que não é simplesmente "aquilo que traduz as lutas ou os sistemas de dominação", mas são em verdade, eles próprios aquilo "porque, pelo que se luta, o poder do qual queremos nos apoderar" (FOUCAULT apud MIGUEL, 2013, p. 324). Bhaskar (2013) denomina a semiologização da realidade como sendo uma conflação da ontologia na linguagem.

Wittgenstein é empurrado para essa semiologização da realidade principalmente pela adoção de Lyotard (2009) dos jogos de linguagem como expressão da realidade, entretanto, na Educação Matemática essa semiologização ocorre a partir da complementação de Wittgenstein por Foucault e Derrida. Para VeigaNeto (2003) o austríaco compartilha das principais teses foucaultianas de não perguntar o porquê das coisas, ao mesmo tempo que compreendem a verdade como algo arbitrário. Nesse sentido, a complementaridade entre Foucault e Wittgenstein se dá pela proximidade entre as práticas discursivas foucaultianas e os jogos de linguagem wittgensteiniano.

Para Duarte e Knijnik (2010) essa proximidade permite compreender como os conteúdos matemáticos, vistos como jogos de linguagem, são em verdade naturalizados e tidos como inquestionáveis. Para as duas autoras, a perspectiva da educação crítica que procura 'aproximar' a matemática escolar da matemática do cotidiano o faz por crer que a matemática escolar é destituída de significado, e nesse aspecto, o cotidiano é quem daria significado a matemática. Não obstante, questionam as autoras se de fato da matemática escolar seria destituída de significado ao ponto de ter que ter de ser transferida para outro jogo de linguagem e assumir significado. Concluem as autoras que a matemática escolar é constituída de significado próprio do seu jogo de linguagem, ao ponto que a defesa dessa transferência da matemática escolar de buscar a realidade do aluno seria uma maneira de transformar a matemática em algo inquestionável e naturalizado. No entanto, as autoras estariam corretas se não fosse por um detalhe: as perspectivas críticas não atribuem uma ausência de significado da matemática escolar em prol do cotidiano. Em verdade, para as perspectivas críticas que defendem a aproximação da matemática escolar da realidade do aluno, principalmente as de base vygotskiana e bakhtiniana, o fazem por compreenderem que os significados não estão presentes em determinados locais e se deve busca-los, mas antes de tudo, são dados nas interrelações sociais dos quais emergem os signos (BAKHTIN, 2006). Isto é, não há uma transferência de significado ou sentido de um jogo de linguagem para o outro, mas antes de tudo, uma ampliação, transformação e uma complexificação desse significado a partir dessas interações.

A semiologização da realidade impede compreender essa relação entre os jogos de linguagem, principalmente por compreender que os mesmos representam formas de vida características, e que como tais jogos de linguagem guardam somente semelhanças de família entre si, igualmente as formas de vida teriam de passar por um processo de tradução. Igualmente, Bakhtin (2006) afirma que os signos são caraterizados por uma tríade (a ideologia, a materialidade histórico-social, e o ponto de vista individual), de forma que essas traduções entre os jogos de linguagem podem produzir novos significados, ampliando ou 
negando os anteriores. E de fato, a perspectiva crítica da educação tem essa compreensão, e não de que os significados seriam transferidos da realidade para a matemática escola sem sofrer mudanças, como querem as autoras.

Em outro caso, Miguel et al (2010) defendem práticas indisciplinares em educação matemática, de maneira que a matemática deixe de ser entendida como uma disciplina e equiparada a um conjunto de conteúdos disciplinares específicos como número, medidas, etc. Em suma, a proposição dos autores é que se faça uma mudança na forma de exposição do conteúdo de maneira que essa mudança possibilite novas formas de relações sociais. Isto é, os autores colocam a carroça a frente dos bois. De maneira excepcional Miguel et al (2010) fazem uma exposição do conteúdo do conhecimento matemático, e de como esse conteúdo se transmuta em diferentes jogos de linguagem dependendo das devidas formas de vida, e assim, advogam que a forma disciplinar da matemática ignora esse conteúdo amplo da matemática. Não poderiam estar mais corretos. Entretanto, ao assumirem que a filosofia terapêutica wittgensteiniana é equivalente, ou muito semelhante, a filosofia desconstrucionista de Derrida, os autores acabam realizando uma profunda confusão entre jogos de linguagem e formas de vida. Quando Wittgenstein afirma que imaginar um jogo de linguagem é imaginar uma forma de vida não afirma que os jogos de linguagem são as formas de vida, e dessa maneira, querer modificar os jogos de linguagem da matemática escolar a partir de práticas indisciplinares não se caracterizariam uma mudança nessas formas de vida. Em verdade, os jogos de linguagem emergem das formas de vida, de maneira que é a transformação nas formas de vida que levam as mudanças nos jogos de linguagem. Como ocorrem essas transformações nas formas de vida que se expressam como transgressões as normas dos jogos de linguagem o filósofo austríaco não dá pistas, isto é, silencia. Seu silêncio sobre as formas de vida deve ser tomado com a devida importância, visto que para Wittgenstein estas formas de vida são, antes de tudo, a expressão própria do mundo donde emergem os jogos de linguagem, e em que estes estão imersos, característica da postura ontológico-religiosa cristã de Wittgenstein.

Desta forma, as tentativas de complementar Wittgenstein com Derrida levam os autores a confundir jogos de linguagem com formas de vida. Nessa direção a semiologização da realidade faz com os autores tentem modificar a forma de vida inserindo arbitrariamente novas normas, desconstruindo as existentes nos jogos de linguagem existentes, ignorando a primazia das formas de vida sobre os jogos de linguagem, sendo estes últimos, teias que preenchem as formas de vida.

\section{O mito da desconstrução como resolução ética}

Antes de adentrarmos as relações entre desconstrução e terapia filosófica, como propostas por Miguel et al (2010) e Miguel (2016), devemos constituir a gênese da desconstrução como conceito e categoria filosófica. Na seção anterior expomos de maneira sucinta a forma como Heidegger falsifica sua própria filosofia de modo que seja perdoado por suas relações com o nazismo, enquanto que as teses centrais de sua filosofia madura, profunda influenciadora de Derrida e Foucault, é adaptação e continuidade da filosofia nazista. 
A desconstrução, como já afirmado anteriormente, tem gênese nessas relações conflituosas entre os filósofos do nazismo. Não obstante, o projeto de desconstrução da filosofia é defendido por Heidegger pela primeira vez em 1955 em um ensaio sobre “A Mobilização Total” de Jünger (FAYE, 1996). Entretanto, a desconstrução de Heidegger é resultado direto das exposições filosóficas de Karl Haeberlin e Ludwig Klages na revista de psicoterapia do Instituto Göring no início dos anos 1930 até a polêmica de 1934, aquilo que Faye (1996) denomina “acontecimento K”. Para Klages, no ensaio Geist als Widerschafer der Seele, existe uma superioridade do espírito da vida e do instinto sobre a civilização e a razão, cunhando assim o termo logocentrismo. Haeberlin verá em Klages a filosofia fundamental da psicoterapia alemã de maneira a defender a desconstrução (Abbau) do logocentrismo em prol do biocentrismo, substituindo os ideais modernos e ocidentais da revolução francesa da liberdade, fraternidade e igualdade, pela tríade alemã da vida, sangue e povo (COCKS, 1997). Em suma, a oposição ao logocentrismo era uma oposição filosófica antissemita.

Agora, cabe a nós procurarmos percorrermos a proposta desconstrucionista dos interlocutores wittgensteinianos no campo da educação matemática. Para Miguel (2016, p. 376) as duas perspectivas, wittgensteiniana e derridiana, partem de um pressuposto "pós-epistemológico da impossibilidade de existência de conhecimento e de pensamento que sejam anteriores, transcendentes ou independentes de jogos de linguagem, no caso de Wittgenstein, ou de escrituras, no caso de Derrida". Desta forma, a narrativas se conformam como um espaço performativo de encenações corporais pela linguagem de maneira que esta já não pode mais ser dissociada das narrativas as quais performa, assim,

não faz mais sentido desconectar a "realidade" de um evento da "realidade" de suas encenações pela linguagem, o que não significa negar a ocorrência efetiva do evento, mas destacar que também essa ocorrência efetiva, para ser significativa, não pode ser independente de sua encenação através de um jogo de linguagem (MIGUEL, 2016, p. 377)

Portanto, para Miguel (2016) não faz mais sentido fazer uma diferenciação entre narrativas ficcionais das narrativas científicas ou 'reais'. Em suma, porque, a partir de uma compreensão derridiana de Wittgenstein, todas essas narrativas necessitam a imersão nos jogos de linguagem. Assim, Miguel (2016) defende o rompimento das fronteiras entre Ficção e História, visto que as duas narrativas são capazes de produzir e desempenhar encenações linguísticas sobre a realidade. Este rompimento como tarefa da desconstrução é justificada por Miguel et al (2010) como uma horizontalização das narrativas, visto que, a desconstrução busca trazer ao centro as retóricas marginalizadas, não em busca de uma nova hierarquização, mas sim em uma dispersão das relações assimétricas estabelecidas entre as concepções hegemônicas (MIGUEL, 2016).

De fato, Miguel (2016) está correto ao defender que também as narrativas ficcionais são capazes de encenar pela linguagem a realidade, entretanto, entre a dispersão das fronteiras da ficção e da história e o combate ao cientificismo hegemônico há uma grande diferença. Se tomarmos esse rompimento das fronteiras como verdadeiro assumiremos que todas as histórias produzidas são sempre ficcionais, por serem necessariamente encenações dentro de determinados jogos de linguagem. Mais do que isso, pelos eventos acontecerem em determinada forma de vida com significações determinadas em seus respectivos jogos de 
linguagem a construção de narrativas históricas seriam sempre produções de tradução de uma forma de vida para outra, e assim, caracterizadas unicamente por semelhanças de família, portanto, ficcionais.

Portanto, advoga Miguel (2016), a partir da filosofia desconstrucionista derridiana, que em Wittgenstein a terapia-gramatical seria uma forma de desconstruir as relações assimétricas estabelecidas entre as narrativas de diversos jogos de linguagem, e, portanto, uma filosofia fundamental para as práticas educativas indisciplinares e transgressoras das disciplinas na educação matemática (MIGUEL et al, 2010). Já expomos anteriormente como essa proposta indisciplinar confunde formas de vida e jogos de linguagem. Não obstante, agora compreendemos as origens dessa confusão ao adotarmos uma postura desconstrucionista na interpretação da terapia gramatical de Wittgenstein.

Os perigos dessa interpretação, e da sua adoção como uma ética, isto é, uma postura de intencionalidade de ação frente ao mundo, nos levam a sermos incapazes de compreender a diferença entre ficção e história, entre verdade e auto-verdade, entre fake News e fato jornalístico. Em suma, como cada forma de vida produz as suas verdades, inerentes a gramática do seu jogo de linguagem, a desconstrução favorece o reaparecimento, a partir das práticas educacionais, das posturas fascistas do século passado, afinal o rompimento entre ficção e fato foi a arma dos meios de comunicações nazistas e fascistas (FAYE, 2009).

Entretanto, a postura dos autores (MIGUEL et al, 2010) não é fascista com relação as propostas indisciplinares, são antes de tudo corretas em parte da análise (como expomos na seção anterior), mas errôneas na sua proposição devido a confusão entre forma de vida e jogo de linguagem. Desta maneira, cabe nos aproximarmos mais dessa proposta dos autores. Para estes, a matemática deve ser vista não como um conjunto de conteúdos, mas como uma família de propósitos, de maneira que a matemática não seja entendida como uma disciplina paralisada em si mesma, mas como uma prática social em que estão envolvidas três dimensões: 1) ações enunciativas, 2) jogos de práticas socioculturais e 3) jogos de práticas socioculturais referenciais. As ações enunciativas são as proposições matemáticas que se caracterizam como normas que regulamentam inequivocamente um jogo de práticas socioculturais aos quais estão normatizando (MIGUEL et al, 2010). Os jogos de práticas socioculturais são os jogos regulamentados pelas ações enunciativas anteriores, enquanto que os jogos de práticas socioculturais referenciais são aqueles que servem de referência como uma atividade humana (MIGUEL et al, 2010).

Nesse sentido, esse processo é o de descontruir "matemática escolar como um domínio especializado de conhecimentos disciplinares" (MIGUEL et al, 2010), e da compreensão da educação escolar como uma prática transmissora de conhecimentos disciplinares, visto que essa organização lança um

Enfeitiçamento disciplinar de ver as matemáticas exclusivamente como um conjunto fixo de conteúdos conceituais típicos - abstratos e genéricos - envolvendo números, medidas, formas geométricas definidas, etc., conformados em um domínio compartimentado e especializado do saber, e que também nos impede de vê-las envolvidas em práticas socioculturais de qualquer natureza realizadas nos contextos de diferentes atividades humanas (MIGUEL et al, 2010, p. 150)

Conquanto os autores proponham uma prática indisciplinar que venha expor as práticas socioculturais envolvidas no ato de praticar matematicamente serem profícuas, o fazem justificando-se de maneira equivocada. Se a organização disciplinar do conteúdo matemático não permite o trabalho da 
matemática como prática sociocultural, sendo necessário a desconstrução da matemática como disciplina, o que explica a existência de tantas experiências socioculturais com matemática vendo a mesma como disciplina? Se tomarmos, por exemplo, a modelagem matemática e toda a discussão socio-crítica da mesma estamos falando de propostas discutem a matemática como conteúdo e como prática sociocultural. Em suma, a justificativa da desconstrução da matemática como corpo disciplinar por parte dos autores não parece estar vinculada com a incapacidade de a compreendermos como prática sociocultural, e sim, na imposição de uma agenda da filosofia pós-estruturalista que busca desconstruir todas as organizações do conhecimento que se centram na razão. Isto é, a justificativa é externa as próprias dificuldades da educação matemática, e externa as próprias demandas societárias, mas tão somente a imposição de uma agenda filosófica ao campo: agenda originária do nazismo.

Esta mesma imposição de agenda é que fará Knijnik e Duarte (2010) verem nas perspectivas críticas da educação agendas de neutralidade, naturalização e imutabilidade da matemática, visto que estas perspectivas seriam "o projeto mais radical da escola moderna" (p. 876), e para esta agenda, se é moderno deve-se desconstruir.

Portanto, é necessário tomarmos a postura desconstrucionista em filosofia da Educação Matemática de acordo com aquilo ela verdadeiramente é: 1) estranha ao corpo teórico de Wittgenstein, 2) continuidade da filosofia nazista, 3) uma agenda para a negação teórica da produção humana até o nazismo.

\section{O mito do eurocentrismo e as posturas identitárias protofascistas}

Ano passado no desfile do Dia da Consciência Negra em São Paulo uma das faixas expostas foi que "miscigenação também é genocídio" (GAZETA DO POVO, 2018), igualmente Garvey (apud BERNARDO, 2018) pronunciava nos anos 1930 que os integrantes do movimento nacionalista africano na Jamaica haviam sido os primeiros fascistas do mundo. Igualmente, percebemos o movimento sionista compreender que a manutenção de sua identidade étnico-racial estar relacionada ao extermínio das identidades palestinas. Rosenberg (2011) já defendia o controle do corpo das mulheres para evitar a miscigenação do sangue nórdico procurando garantir assim a pureza do sangue ariano, não obstante em um discurso para o partido nazista Hitler (apud BERNARDO, 2018) afirma que

reconhece a presença no nosso povo de diferentes substâncias raciais. Não pretendo de modo nenhum rejeitar, em si, essa mescla. [...] Desejo, no entanto, que a direção política e cultural do nosso povo conserve o rosto e a expressão da única raça que, graças ao seu heroísmo e as suas predisposições interiores, forjou o povo alemão a partir de um conglomerado de componentes variados (p. 886)

Este modelo nazista de que para confirmar uma raça necessitava de uma antirraça se confirma com as perspectivas identitárias atuais, com um pequeno empecilho, o eurocentrismo não é algo assim tão homogêneo. No entanto, da mesma forma que o antissemitismo colocava os judeus como os inimigos da manutenção de sua raça, as posturas identitárias colocam hoje o eurocentrismo como inimigo da sua manutenção como identidade étnico-racial. 
Quando apontamos o eurocentrismo ${ }^{1}$ como um mito histórico não o fazemos por negar que há um processo de apagamento cultural em voga na educação, somente que este processo não tem relação material nem social com um povo europeu. Mito eurocêntrico porque não corresponde aos fatos históricos, afinal, o que é esse povo europeu que hegemoniza para si a cultura? Devo, nesse sentido trazer uma longa citação que sintetiza esse mito histórico-social, afirma Bernardo (2018, p. 1367) que

A civilização grega e a romana, consideradas a matriz da Europa, na realidade foram mediterrânicas e não europeias. $\mathrm{E}$ foram-no em sentido lato, visto que a Grécia assimilou conhecimentos não só do Egipto mas igualmente da Babilónia. O império de Alexandre tomou como base aquela rede de relações e chegou mais longe, porque levou à Índia a sabedoria grega e, em sentido inverso, trouxe para o Mediterrâneo elementos do pensamento indiano. O império romano ampliou esta área de influências recíprocas, continuando a ter como centro o Mediterrâneo. Depois, apesar da ruptura provocada pela difusão do islamismo a órbita mediterrânica não se desfez, graças ao movimento de traduções para a língua árabe ocorrido no califado abássida a partir dos meados do século VIII e que culminou no primeiro terço do século seguinte sob o califa al-Ma'mūn. De um lado traduziram-se originais gregos e do outro, textos em sânscrito e em persa. Aliás, como os abássidas estiveram particularmente ligados à cultura persa, as relações transmediterrânicas nessa época atingiram um escopo mais vasto, considerando ainda que a relação dos muçulmanos com a Índia alterou as noções de matemática a sul e depois a norte do Mediterrâneo. E haveria também que mencionar o judaísmo ibérico como ponte entre as correntes filosóficas em curso na cultura islâmica e o novo pensamento filosófico que despontava além-Pirenéus. Assim, quando a partir do século XII se iniciou o movimento de traduções do árabe para o latim, a cristandade ocidental não só voltou a conhecer a filosofia e a ciência gregas mas ampliou o âmbito geográfico das suas inspirações.

Por outro lado, quando analisamos as obras de filósofos árabes contemporâneos e a maneira com que analisam a formação europeia afirmam que a cultura árabe é a ponte entre a cultura grega e a cultura atual, de forma que o povo europeu atual é fruto do islamismo medieval (AL-KHALILI, 2012; YABRI, 2016), por outro lado, a possibilidade de uma cultura europeia de fato somente vai se confirmar ao longo do século XIX em que ocorre a ascensão do capitalismo, sendo este na verdade no campo cultural a integração e absorção de diversas culturas mundiais em uma cultura unificada (BERNARDO, 2018). Portanto, a crença do eurocentrismo como uma cultura que se quer hegemônica e opressora das culturas que sofrem o apagamento, as mortes epistemológicas como afirma a perspectiva pós-colonial, é em verdade um deslize da questão central do Capital para a cultura europeia. Isto é, assim como fascismo europeu, evitando compreender o capitalismo e a propriedade privada como originária das problemáticas sociais da guerra, compreendeu as raças não-arianas como as culpadas pelo sofrimento do povo alemão, igualmente as perspectivas identitárias compreende o eurocentrismo como culpado por essa opressão para poder ignorar o capitalismo. Na outra dimensão, quando criticam o caráter excludente do capitalismo não o fazem sob uma perspectiva crítica do capital, mas sim crítica com relação do acesso ao capital, isto é, o mito da representatividade.

\footnotetext{
1 Aqui estamos tratando exclusivamente da concepção de eurocentrismo vinculada a agenda pós-moderna. As críticas de matriz marxista ou latino-americana ao eurocentrismo não estão sendo consideradas.
} 
E por outro lado, quando se opõe à cultura europeia está se opondo a grande parte das conquistas culturais feitas pelos trabalhadores de todo o mundo, visto que esta cultura eurocêntrica é a cultura mundial resultante dos conflitos sociais e das lutas socias emancipatórias do proletariado. Este opor-se a cultura europeia em prol de uma produção cultural livre dela é a mesma postura adotada por Krieck com relação a Heidegger quando afirma que sua filosofia era digna de literatos judeus. Isto é, não se está preocupado com o avanço epistêmico dos conhecimentos quando se critica o eurocentrismo, o homem branco e heterossexual, mas sim está se preocupado em criar epistemologias libertas dessa cultura europeia, procurando abandonar a miscigenação epistemológica com a mesma postura, novamente, equivalente as filosofias nazistas expressas por Rosenberg (2011).

Este é uma temática recorrente nas posturas adotadas por etnomatemáticos de viés pósestruturalistas, pois acusam a matemática disciplinar de ser eurocêntrica e opressora. Knijnik (2017, p. 54) busca analisar, a partir da interação teórica de Wittgenstein e Foucault, os "discursos eurocêntricos da matemática acadêmica e da escolar e seus efeitos da verdade" ao mesmo tempo que conclui que a matemática eurocêntrica repele para fora do seu jogo de linguagem práticas que não se conformam a forma abstrata e formalista desta matemática. Em Knijnik (2007) defende-se que a postura de cubagem de terra dos semterra do Rio Grande do Sul não seria considerada uma prática verdadeira por parte da matemática eurocêntrica, pois segundo ela, para a matemática eurocêntrica as respostas e os cálculos devem ser sempre exatos, e o método da cubagem de arredondar pra cima e pra baixo não traria essa certeza.

Knijnik (2007) está correta nessa afirmação, pois a forma da matemática acadêmica é baseada na ideologia da certeza (SKOVSMOSE, 1999). Entretanto, para a autora a compreensão desse jogo de linguagem como sendo um jogo de linguagem matemático é dado em grande parte pela semelhança de família atribuído a matemática eurocêntrica e a matemática dos sem-terra. A possibilidade da autora de compreender essas práticas de cubagem como práticas socioculturais (MIGUEL et al, 2010) do fazer matematicamente advém da compreensão da matemática eurocêntrica. Em suma, mesmo nos trabalhos de Miguel et al (2010) onde buscam transgredir a ideia de matemática como campo de conteúdos construindo a concepção de matemática como seguir uma regra inequívoca o fazem partindo da existência e da compreensão da matemática eurocêntrica. Isto é, não há como prescindir da matemática eurocêntrica, em seu conteúdo, para um estudo etnomatemático.

O que ocorre na verdade nas afirmações de que existem outras matemáticas que não a matemática eurocêntrica, seja lá o que for isso, é a confusão entre forma e conteúdo. Quando adotamos a perspectiva filosófica de Wittgenstein estamos descrevendo, mostrando, as diferentes formas de prática da matemática, e mais do que isso, a partir de Wittgenstein nega-se a existência de um conteúdo matemático. Entretanto, essa negação do conteúdo matemático, dessa essência, não corresponde a negar a matemática eurocêntrica como possibilidade universalizante da cultura, ou a Matemática como dotada de uma característica universal (GIARDINETTO, 2000). Em suma, a matemática eurocêntrica corresponde a uma forma matemática característica do mundo globalizado e tecnicista em que a mesma necessita servir para aplicações em outras ciências ao mesmo tempo que se estabelece como detentora, transferidora e construtora da verdade (SILVEIRA e WAGNER, 2017). Portanto, quando Knijnik (2017) aponta a matemática eurocêntrica como 
aquela que se quer universal e única está confundido questões importantes do desenvolvimento deste importante complexo social. Ao assumir que a matemática é somente uma linguagem pela qual se normatiza a maneira de ver e entender o mundo, e que seu vínculo com as formas de vida ocorre pela cristalização de proposições empíricas em proposições gramaticais perdemos a oportunidade de compreender o conteúdo da matemática para além de sua manifestação cotidiana como forma. Badiou (1978) já apontava que no formalismo matemático, isto é, na sua exposição formal, estavam presentes como conteúdo todas as contradições que se moveram para constituir essa forma final. No entanto, para isso é necessário compreender que essa forma final, mais desenvolvida da matemática é, ela mesma, mutável e detentora de história marcada de continuidades e descontinuidades. Por conseguinte, sua universalidade não se refere a uma questão invariante, mas antes disso, a uma compreensão de que seu conteúdo é expressão mais desenvolvida do conhecimento matemático produzido pela humanidade podendo ser modificado de acordo com o desenvolvimento histórico da humanidade.

Portanto, é mister compreendermos que a forma é sempre uma relação posta com o conteúdo (LUKÁCS, 2013), de maneira que aquilo que Knijnik (2017) afirma ser uma matemática eurocêntrica que se quer universal, e portanto, opressora, nada mais é que a manifestação de uma forma como relação posta com o conteúdo. Esta relação posta não é resultado de uma identidade cultural europeia, mas sim pela própria dinâmica do capitalismo que requer uma forma determinada do conhecimento matemático que produza resultados exatos e sirva aos interesses ideológicos. O conteúdo matemático, como categoria universal, está oculto nessa forma não por se esconder, mas porque sua compreensão requer uma postura histórica de análise compreendendo em cada bic et nunc as relações postas entre forma e conteúdo da matemática.

\section{Pragmatismo ou neotecnicismo?}

Enquanto a maior parte dos autores se aproxima de uma perspectiva pós-estruturalista ou pósmetafísica (MIGUEL et al, 2010), os trabalhos de Gottschalk $(2007,2008)$ procuram aproximar a filosofia de Wittgenstein de uma concepção pragmática da educação matemática.

Para Gottschalk (2008), apoiada em Wittgenstein, a matemática é responsável em nossa vida por proibir e permitir certas inferências. Por outro lado, a postura antiessencialista carregaria consigo a impossibilidade de haver essências atribuídas aos números racionais, por exemplo, ao qual os alunos pudessem se aproximar bastando que seguissem resolvendo os problemas postos. Isto é, o aluno não vai se aproximando per si de uma essência cada mais vez ampla dos números, mas sim uma "nova aplicação é sugerida para o conceito de número, diferente das demais, mas que tem umas semelhanças de família com as anteriores" (p. 85), assim, não trata do aluno descobrir um novo número a partir de um problema, pois um problema só é um problema quando "a questão tem um sentido, e há um caminho apenas no sistema em que a questão está colocada" (GOTTSCHALK, 2008, p. 85-86). Cabendo assim ao professor apresentar estas novas aplicações, num sentido convencional, onde esse ensino do significado necessita vir 
acompanhado de "atividades intrinsecamente ligadas a linguagem" (GOTTSCHALK, 2008, p.86) da matemática, visto que a compreensão sempre se dá internamente ao jogo de linguagem.

Desta forma Gottschalk (2007) defende uma concepção de ensino e aprendizagem no qual o professor exerce papel importante na transmissão dos conhecimentos matemáticos a partir dos usos desses novos conhecimentos/conceitos no contexto linguístico. E este apreender o conceito matemático requer que o professor treine o aluno na técnica, pois é somente pelo treino na técnica que os novos conceitos irão adquirir sentido para o aluno e não por formas "intuídas ou descobertas" (GOTTSCHALK, 2008, p. 88)

Portanto, afirma Gottschalk (2008), que existem conteúdos que não são aprendidos no seu sentido usual, pois assim, como no aprender a subir a montanha a existência da montanha está implícita, igualmente ocorre com alguns conceitos matemáticos. Esse aprender de não maneira não usual é baseado na crença e na autoridade do professor que seja capaz de convencer os alunos disto.

Assim, o ensino de matemático é normativo, que pode partir de algumas proposições empíricas, mas se direciona a confirmar as convenções matemáticas. Por exemplo um triângulo deve ter 3 lados e seus ângulos internos somados resultam em $180^{\circ}$, de forma que a crença do aluno nesse fato não advém de uma medida de vários ângulos internos de vários triângulos, mas sim da afirmação presente como crença e convenção nas falas dos professores e nos textos dos livros didáticos (GOTTSCHALK, 2008).

A prática do professor de apresentar exemplos para que o aluno compreenda os significados desses novos conceitos é característica fundamental do mestre como alguém que apresenta "outros pontos de vista, outras formas de ver, com o objetivo de persuadi-lo a aceitá-los" (GOTTSCHALK, 2008, p. 91), assim conclui a autora que a partir de Wittgenstein se constitui uma visão pragmática da educação onde caberia ao professor apresentar essas novas crenças e a partir da sua autoridade convencer aos estudantes do caráter verdadeiro dessa convenção, visto que ao professor cabe um papel que busque ir contra as tendências contrárias dos alunos dado o caráter diferente desses novos conceito com relação aos usos cotidianos da linguagem (GOT'TSCHALK, 2007).

Em suma, para Gottschalk a filosofia wittgensteiniana defende uma postura pragmática do ensino, como um ato de treinar o estudante nesse novo uso e nessas novas normas que surgem. Considero que a constatação de uma postura pragmática na educação por parte de Wittgenstein é a mais correta dentre todas, visto que o mesmo já afirma que é necessário que os alunos sejam treinados nos jogos de linguagem, assumindo suas regras e assim podendo utilizá-los. Isto é, diferente das posturas pós-metafísicas que buscam em Wittgenstein um crítica da razão moderna, ao logocentrismo e desconstrucionista, Gottschalk (2007, 2008) resgata as reais compreensões do austríaco com relação a educação, naquilo que o mesmo compreendia como ensino ostensivo, e que nos capítulos anteriores vínhamos denunciando: uma postura pública da linguagem, na qual as pessoas precisam ser treinadas para poder usufruir livremente delas. Nesse sentido, concordo com Gottschalk $(2007,2008)$ que há uma postura pragmática, sem, no entanto, seguir essa postura. Em suma, a postura pragmática de Wittgenstein no ensino ostensivo como ensino de treinar para uma técnica é só uma outra forma de defesa de um ensino tecnicista que não questiona que conteúdos são estes, ou o porquê deles, mas sim que devem ser acatados, aceitos e apreendidos. Isto é, para 
Wittgenstein a postura de ampliação do ensino da matemática para fora da disciplina somente se justificaria se auxiliasse no aumento dos usos e das significações desses conceitos no próprio jogo de linguagem.

\section{Consideração Final}

Nesse sentido, podemos concluir como questão fundamental que a filosofia de Wittgenstein é corpo estranho com relação as filosofias pós-metafísicas, ao mesmo tempo, que seu silêncio ontológico, como ausência explícita de teoria social e da história, permitiu que fossem acoplados a sua filosofia tais tendências. E por outro lado que o pragmatismo wittgensteiniano pode ser considerado uma maneira mais sofisticada de defesa de uma postura tecnicista do ensino de matemática.

\section{Referências}

ADORNO, TW. "Educação após Auschwitz”. In: Educação e Emancipação. $3^{a}$ Ed. São Paulo: Paz e Terra. Tradução de Wolfgang Leo Maar p. 119-138, 2003.

ALEKSANDROV, A. D.; KOLMOGOROV, A. N. \& LAVRENT'EV, Mikhail Alekseevich. Mathematics: its content, methods, and meaning. Massachusetts: M.I.T. Press, 1963.

AL-KHALILI, J. Pathfinders. The Golden Age of Arabic Science, Londres: Penguin, 2012.

ANDERSON, P. Components of the national culture. New left review, n. 50, p. 3, 1968.

ARCHER, M. S. Realist social theory: The morphogenetic approach. Cambridge university press, 1995.

BADIOU, A. La antifilosofía de Wittgenstein. Capital Intelectual, 2013.

BAKHTIN, M. Marxismo e filosofia da linguagem: problemas fundamentais do método sociológico da linguagem. São Paulo: Hucitec, 2006.

BERNARDO, J. Labirintos do Fascismo. Domínio Público, disponível em < https://archive.org/download/jb-ldfnedoedr/BERNARDO $\% 2 \mathrm{C} \% 20 \mathrm{Jo} \% \mathrm{C} 3 \%$ A3o.\%20Labirintos $\% 20 \mathrm{do} \% 20$ fascismo. $\% 203 \% \mathrm{C} 2 \%$ AA $\% 20$ ed i\%C3\%A7\%C3\%A3o.pdf > acessado em 28/10/2018 às 21:06, 2018.

BHASKAR, R. A realist theory of science. London: Routledge, 2013.

COCKS, G. Psychotherapy in the Third Reich: The Goering Institute. Transaction Publishers, 1997.

CONANT, J.; DIAMOND, C. Rileggere Wittgenstein. Carocci Editore: Roma, 2010.

CONDÉ, M.L.L. As teias da Razão: Wittgenstein ea crise da racionalidade moderna. Argumentum, 2004.

CONDÉ, M.L.L. Wittgenstein: linguagem e mundo. São Paulo: Annablume, p. 114, 1998.

DELLA FONTE, SS. As fontes heideggerianas do pensamento pós-moderno. 2006. 233 f. Tese de Doutorado. Tese (Doutorado em Educação) - Centro de Ciências da Educação, Universidade Federal de Santa Catarina, Florianópolis, 2006.

DUAYER, M; MORAES, MCM. História, estórias: morte do real ou derrota do pensamento. Perspectiva, v. 16, n. 29, 1998.

FAYE, JP. Introdução às linguagens totalitárias: teoria e transformação do relato. Perspectiva, 2009.

FAYE, JP. razão narrativa, A. São Paulo: Editora 34, 1996.

GAZETA DO POVO. "Miscigenação entre brancos e negros é, na verdade, genocídio?" Disponível em https://www.gazetadopovo.com.br/ideias/miscigenacao-entre-brancos-e-negros-e-na-verdade-genocidio4911 f8ymfw42mye601 rrw6iqk/. Acesso em 10/11/2018. 
GIARDINETTO, JRB. Reflexões sobre o papel da escola e do ensino de matemática em tempos de globalização: multiculturalismo e/ou'monoculturalismo'. X Seminário de Investigação em Educação Matemática. Portimão, Portugal, v. 8, p. 27, 2000.

GOTTSCHALK, C. A construção e transmissão do conhecimento matemático sob uma perspectiva wittgensteiniana. Cadernos Cedes, v. 28, n. 74, p. 75-96, 2008.

GOTTSCHALK, CMC. Uma concepção pragmática de ensino e aprendizagem. Educação e pesquisa, v. 33, n. 3, p. 459-470, 2007.

HEIDEGGER, M. "Only a God Can Save Us": The Spiegel Interview (1966). In: Heidegger. Routledge, 2017. p. 45-68.

HEIDEGGER, M. Die Kehre. Alcion Editora, 1991.

HEIDEGGER, M. Carta sobre o humanismo. São Paulo: Centauro, 2005b.

HEIDEGGER, M. Ser e Tempo, vol. I e II. Petrópolis: vozes, 2005a.

HELLER, Agnes. O Cotidiano e a História. São Paulo: Paz e Terra, 2000.

KNIJNIK, G. et al. Etnomatemática em movimento. Autêntica, 2018.

KNIJNIK, G. A ordem do discurso da matemática escolar e jogos de linguagem de outras formas de vida. Perspectivas da Educação Matemática, v. 10, n. 22, 2017.

KNIJNIK, G. Mathematics education and the Brazilian Landless Movement: three different mathematics in the context of the struggle for social justice. Philosophy of Mathematics Education Journal, v. 21, p. 1$18,2007$.

KNIJNIK, G. Exclusão resistência: educação matemática e legitimidade cultural. Artes Médicas, 1996.

LUKÁCS, G. Para uma ontologia do ser social-vol. 1. São Paulo: Boitempo, 2012.

LUKÁCS, G. Para uma ontologia do ser social-vol. 2. São Paulo: Boitempo, 2013.

LYOTARD, J. A Condição Pós-Moderna. Jose Olympio Editora: Rio de Janeiro, 2009.

MARGUTTI, P.G. A questão da continuidade do pensamento de Wittgenstein. In: Guido Imaguire; Maria Aparecida Montenegro; Tarcísio Pequeno. (Org.). Colóquio Wittgenstein. Artigos em comemoração ao cinquentenário das Investigações Filosóficas. Fortaleza: Edições UFC, 2006, v. , p. 13-54.

MARX, K. Grundrisse: esboço da crítica da economia política. São Paulo: Boitempo, 2011.

MARX, K. O Capital: crítica da economia política, Livro 1. São Paulo:DIFEL Difusão Editorial, 1982.

MÉSZÁROS, I. O poder da ideologia. São Paulo: Boitempo, 2004.

MIGUEL, A. Historiografia e terapia na cidade da linguagem de Wittgenstein. Boletim de Educação Matemática, v. 30, n. 55, 2016.

MIGUEL, A. Posfácio ao livro Usos e jogos de linguagem na matemática: diálogo entre Filosofia e Educação Matemática. VILELA, Denise Silva. São Paulo (SP): Editora Livraria da Física, p. 319-348, 2013.

MIGUEL, A.; VILELA, D. S.; MOURA, A. R. L. de. Desconstruindo a matemática escolar sob uma perspectiva pós-metafísica de educação. Zetetiké, Campinas, v. 18, p. 129-206, 2010.

MONK, R. Ludwig Wittgenstein: el deber de un genio, 2 ed. Anagrama, Barcelona, 1997.

MORAES, MCM. Iluminismo às avessas: produção de conhecimento e políticas de formação docente. Rio de janeiro: DP\&A, p. 80-98, 2003.

ROCKHILL, G. The Cia Reads French Theory: On The Intellectual Labor Of Dismantling The Cultural Left, 2017. Disponível em: http:/ / thephilosophicalsalon.com/the-cia-reads-french-theory-on-theintellectual-labor-of-dismantling-the-cultural-left/, acessado em 10/11/2018.

RORTY, R. A filosofia e o espelho da natureza. Relume Dumará, 1994. 
SILVEIRA, E; WAGNER, G. Tecnologia E Os Modelos Matemáticos: Reflexões Crítico-Ontológicas. VIDYA, v. 37, n. 1, p. 91-108, 2017.

VEIGA-NETO, A. Foucault \& a Educação. Belo Horizonte: Autêntica, 2003.

VIGOTSKI, LS. A construção do pensamento e da linguagem, Martins Fontes: São Paulo, 2001.

VILELA, D S. Usos e jogos de linguagem na matemática: diálogo entre filosofia e educação matemática. São Paulo: Editora Livraria da Física, 2013.

VILELA, DS. Matemáticas nos usos e jogos de linguagem: Ampliando concepções na Educação Matemática. Tese de Doutorado UNICAMP, 2007.

WAGNER, G; SILVEIRA, E. Reflexões Ontológicas Em Educação Matemática: Heidegger E A Perspectiva Da Educação Matemática Crítica. Revista de Educação, Ciências e Matemática, v. 7, n. 2, 2017.

WITTGENSTEIN, L. Investigações filosóficas. Trad. José Carlos Bruni. São Paulo: Nova Cultural, 1991.

WITTGENSTEIN, L. Tractatus logico-philosophicus. São Paulo: Companhia Editora Nacional, 1968.

WITTGENSTEIN, L. Observaciones sobre los fundamentos de la matemática. Madrid: Alianza, 1987.

YABRI, MH. El Legado Filosófico Árabe. Alfarabi, Avicena, Avempace, Averroes, Abenjaldún. Lecturas Contemporáneas, Madrid: Trotta, 2016.

\section{Notas:}

${ }^{1}$ UFSC. Graduado em Matemática (UFSC). Metre e Doutorando em Educação Científca e Tecnológica (UFSC). Professor de Matemática do projeto de Educação Popular Integrar. ORCID: http://orcid.org/0000-0003-1346-7980 Email: guilherme.w@posgrad.ufsc.br

2 Graduado em Licenciatura em Matemática, Especialista em Educação Matemática pela Universidade Federal de Ouro Preto-MG e Mestre em Educação, na linha Educação Matemática, pela Universidade Federal do Paraná e Doutor em Educação Científica e Tecnológica, na linha Educação Matemática, pela Universidade Federal de Santa Catarina. Professor Adjunto DE do Departamento de Metodologia de Ensino da Universidade Federal de Santa Catarina. ORCID: http://orcid.org/0000-00031346-7980 Email: derelst@hotmail.com 